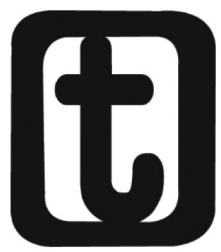

\title{
A CRISE DO CAPITAL, O DESASTRE SOCIAL E A ORIENTAÇÃO TEÓRICO-METODOLÓGICA DAS POLÍTICAS SOCIAIS
}

\author{
THE CAPITAL OF CRISIS, SOCIAL DISASTER AND THE THEORETICAL- \\ METHODOLOGICAL ORIENTATION OF SOCIAL POLICIES
}

\section{Patricia Soraya Mustafa'}

\section{RESUMO}

Este artigo almeja, a partir de um determinado contexto histórico, o da crise do capital no seu estágio monopólico financeiro, demonstrar os impactos desta crise para a classe trabalhadora, compreendendo como um destes impactos o recrudescimento dos direitos sociais, levado a cabo pelos governos neoliberais. Para tanto, explicitaremos com contributos de alguns autores que se trata de uma crise permanente que produz e reproduz consequências catastróficas em todas as regiões do globo. E por último, apresentaremos o referencial teórico-metodológico que respalda as políticas sociais brasileiras nos últimos governos Lula-Dilma, o que evidenciará a opção política e econômica destes governos.

Palavras-chave: Crise do Capital. Neoliberalismo. Políticas Sociais. Governos Lula-Dilma.

\section{ABSTRACT}

The article demonstrates the impacts of the actual financial crisis for the working class in a specific context, which is the crisis of the capitalist

\footnotetext{
1 Assistente Social. Doutora em Serviço Social pela UNESP-Franca. Pós-doutora pela Universidade Católica Portuguesa - Lisboa (UCP-Lisboa). Professora do Curso de Serviço Social da UNESP/Franca. Coordenadora do Grupo de Estudos e Pesquisa em Políticas Sociais (GEPPS) e Pesquisadora do Grupo Teoria Social de Marx e Serviço Social.
} 


\section{tempordlis}

system in its monopoly stage. It is intend to link those impacts with the reduction of the social rights made by neoliberal governments in the last decades. Besides, it is discuss the permanent character of this crisis around world, on the contrary to some discourses that present it as an incidental crisis which can be overcome. In that context, it is presented the theoretical and methodological approaches to social policies in Brazil conducted by the last governments of Lula and Dilma. The aim is to discuss about the political and economic options that guide this polices in there cent times.

Keywords: Capital Crisis. Neoliberalism. Social Policies. Lula - Dilma Governments.

Submetido - 15/03/2015

Aceito - 19/05/2015

Assim como defende A perfeição da flor Acabada

E em si mesma fechada,

O poeta não defende Até hoje governo algum:

Seu lado é o lado do povo Sempre e sempre roubado Por mil, por cem ou por um.

O pelego se untou Nas banhas do negocista

E engordou engordou

Tanto

Que a sua barriga tão grande

Esmagou

A menina do povo Que vinha com a flor, Que vinha com a flor.

[...]

(Moacyr Félix - Canto para as transformações do homem, 1964).

\section{INTRODUÇÃO}

Se as políticas sociais ganharam terreno no pós-Segunda Guerra Mundial, e aliadas ao modelo fordista de produção provocaram crescimento econômico e desenvolvimento social nos países de capitalismo central, sob o capitalismo monopólico financeiro, pautado na flexibili- 
zação do trabalho, no mantra da privatização e do ajuste fiscal, os direitos sociais perdem terreno - os serviços sociais públicos - são voltados não mais para todos, mas para os extremamente pobres, e os serviços privados oferecidos aos consumidores que por eles podem pagar.

O capital monopólico financeiro, permanentemente em crise, busca novos nichos para sua expansão, e, neste sentido, os direitos sociais passam a ser campo de exploração do mercado e tornam-se mercadorias postas à banca de produtos a serem vendidos, não mais para os cidadãos, mas para os consumidores.

Os trabalhadores nesse ínterim são golpeados duplamente - pelas transformações no campo do trabalho, flexibilizado, precarizado, e pela violação de seus direitos trabalhistas e sociais em geral, tendo em vista o escopo que estes adquirem no tempo presente.

A partir destes pressupostos, pretende-se, através de um estudo realizado com dados secundários e fontes bibliográficas, problematizar estas questões nas páginas que se seguem, sem a pretensão de esgotá-las e tampouco concluí-las, mas com o ímpeto de contribuir neste debate, fundamental ao Serviço Social.

\section{A CRISE DO CAPITAL E O DESASTRE SOCIAL}

Desde a crise econômica de 1973, as ideias neoliberais começam a ser difundidas e implementadas sob o argumento de que:

[...] o bem-estar humano pode ser melhor promovido liberando-se as liberdades e capacidades empreendedoras individuais no âmbito de uma estrutura institucional caracterizada por sólidos direitos a propriedade privada, livres mercados e livre comércio. (HARVEY, 2008, p. 12).

Desta forma, cabe ao Estado a garantia dessas liberdades. Instaura-se a partir de então um processo de contrarreforma ${ }^{2}$ que se leva a cabo pautado no ajuste fiscal, na desregulamentação dos mercados, na privatização do setor público, na redução do Estado, na desmontagem do sistema de proteção social e flexibilização do mercado de trabalho.

2 O sentido de reforma, segundo Paulo Netto e Braz (2007) perde o sentido tradicional de mudanças para conquistas e ampliação de direitos, para um processo inverso, por isso contrarreforma. 


\section{temporalis}

Estas mudanças impactam diretamente o campo das políticas sociais: o Estado deixa de ser o protagonista na garantia dos direitos sociais; em detrimento destes, incentiva-se os indivíduos a serem empreendedores; a satisfação das necessidades sociais perde campo para a satisfação das necessidades do mercado (PEREIRA, 2010); empreende-se reformas nos sistemas de previdência social que, segundo as indicações do teórico neoliberal, Milton Friedmann, devem ser contratados" "[...] individualmente e gerido por um sistema de capitalização" (apud PEREIRA, 2010, p.8); há a substituição do princípio da universalização pelo princípio da focalização e o resgate "[...] da filantropia privada que passou a ter notável estímulo no quadro de um modelo de bem-estar que perdeu o protagonismo do Estado e passou a ser denominado de bem-estar misto ou pluralista (welfaremix)." (PEREIRA, 2010, p.9).

O que se percebe é que estes impactos se agravam ainda mais com a crise do capital que eclode em 2008. Trata-se, segundo Mészáros (2011) de uma crise "[...] endêmica, cumulativa, crônica e permanente", pois, de acordo com este autor o capitalismo não alterna mais períodos de expansão e crise, mas se apresenta a partir das décadas de 1960 e 1970 imerso numa depressed continuum, caracterizando o que denomina de crise estrutural do capital. Assim nos explica Mészáros (2011, p. 11, grifo do autor):

[...] o sistema de capital, por não ter limites para sua expansão, acaba por converter-se numa processualidade incontrolável e profundamente destrutiva. Conformados pelo que se denomina, na linhagem de Marx, como mediações de segunda ordem - quando tudo passa a ser controlado pela lógica da valorização do capital, sem que se leve em conta os imperativos humano-societais vitais -, a produção e o consumo supérfluos acabam gerando a corrosão do trabalho, com a sua consequente precarização e o desemprego estrutural, além de impulsionar uma destruição da natureza em escala global jamais vista anteriormente.

Essa crise estrutural marcada pela separação radical entre produção para as necessidades sociais e para a autorreprodução do capital - ênfase do capitalismo contemporâneo - traz consequências devastadoras para a humanidade: pela precarização estrutural do trabalho e a destruição da natureza - a corrosão do trabaIho contratado e regulamentado, herdeiro da era taylorista e fordista (séc. XX), resultado de lutas operárias por direitos sociais, 
é substituído pelo empreendedorismo, cooperativismo, trabalho voluntário, o que Vasapollo (2005) chama de "trabalho atípico". Formas que variam da superexploração a autoexploração do trabalho. Sem falar no desemprego estrutural, crescente e que vem aumentando assustadoramente nos países de capitalismo central. Mészáros (2011, p. 20) cita o jornal The Economist que apontava em outubro de 2008 os impactos da crise:

O dano para a economia real está se tornando aparente. Nos Estados Unidos, o crédito ao consumidor está se contraindo, e cerca de 150 mil americanos perderam os seus empregos em setembro, o recorde desde 2003. Algumas indústrias estão seriamente prejudicadas: as vendas de carros estão no seu mais baixo patamar em dezesseis anos, pois os potenciais compradores são incapazes de obter crédito. A General Motors fechou temporariamente algumas das suas fábricas na Europa. Por todo globo indicadores prospectivos, como inquéritos de compras junto a administradores, estão terrivelmente sombrios.

O capitalismo contemporâneo, na sua fase monopólica financeira, segundo um estudo apresentado por Mészáros (2011) do Presidente do Partido Comunista do Japão, de outubro de 2008, mostra que a economia real global (produção e comercialização), nas duas últimas décadas, movimentava 48,1 trilhões de dólares, enquanto a economia financeira 151,8 trilhões de dólares, ou seja, três vezes mais. Isso mostra o tamanho do fosso entre a economia real e a financeira.

Assim, Mészáros (2011) afirma que “[...]a expansão especulativa do aventureirismo financeiro" é intrinsecamente relacionada ao "[...] aprofundamento da crise dos ramos produtivos da indústria, a expressão mais contundente desta crise é aumento do desemprego e a miséria humana a ele associada."

Outro elemento importante destacado por Mészáros (2011) é a simbiose existente entre as grandes companhias e o Estado capitalista. Ele cita em seu livro um estudo do Cato Institute, o qual aponta que o governo dos Estados Unidos da América (EUA) injetou 92 bilhões de dólares nos negócios em 2006, destes, 21 bilhões foram destinados aos agricultores, e a maior parte do restante para a Boeing, International Business Machines (IBM), General Eletric. Segundo Mészáros (2011, p. 137) esta crise é estrutural porque não pode ser superada "[...] nem mesmo com os muitos trilhões de operações de resgate dos Estados 


\section{tempordlis}

Capitalistas."

Enquanto isso ... e os trabalhadores? Estão sendo convencidos de que devem "apertar os cintos", "aceitar os sacrifícios necessários", o que inclui cortes e congelamento dos salários, ataques aos direitos trabalhistas, em nome de quê? Da estabilização do sistema do capital.

Sem falar as discrepâncias nos salários ocasionados pelo "[...] imperialismo global hegemônico", para citar um exemplo, trabalhadores da linha de produção da Ford nas Filipinas ganham um "[...] salário-hora 25 vezes menos que seus irmãos de classe das fábricas da Ford de Detroit (EUA)." (MÉSZÁROS, 2011, p. 148).

Assim, pode-se dizer que a intervenção do Estado em favor do mercado financeiro e dos grandes monopólios produtivos agrava ainda mais a questão social, segundo lamamoto (2009).

Para atestar o que estamos falando, alguns dados:

\section{Gráfico 1 - Desemprego na Europa}

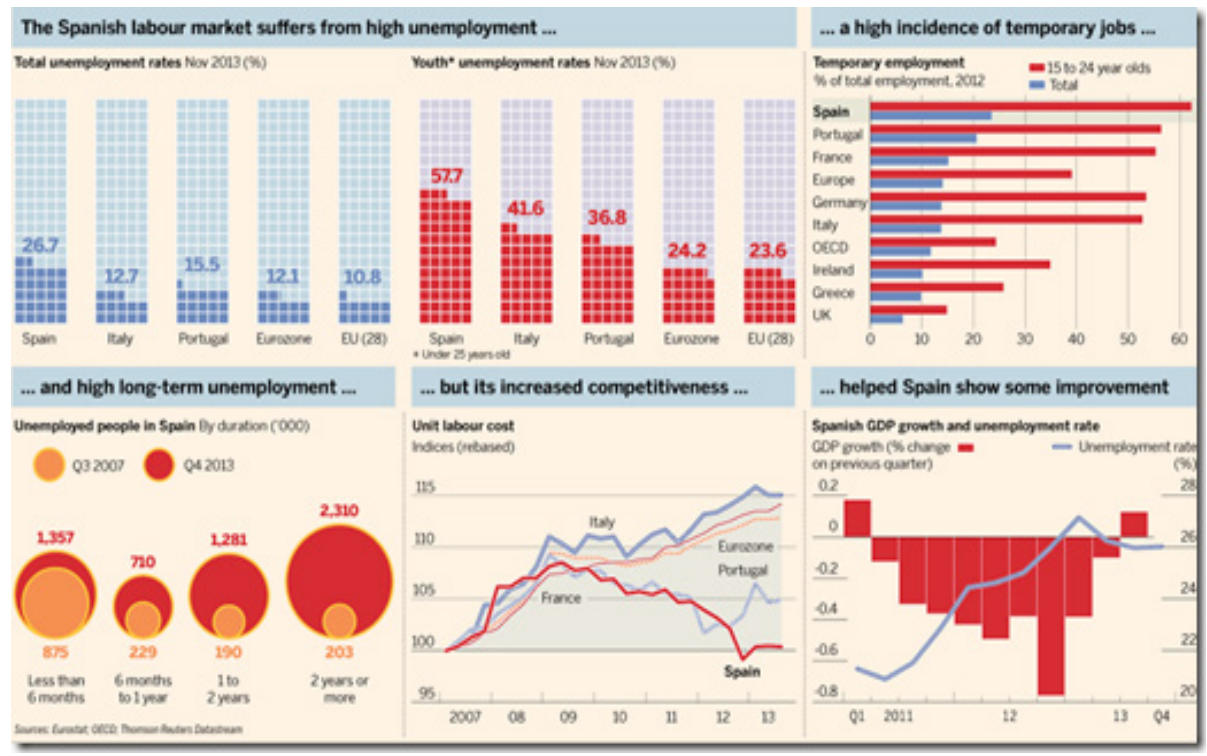

Fonte: CASADEI, 2014, on-line. 


\section{tempordlis}

Ao olhar para estes dados de 2013, considerando a população economicamente ativa, tem-se que: dentre os espanhóis (todas as faixas etárias) $26,7 \%$ estão desempregados e 17,6\% são temporários, totalizando 44,3\% destes trabalhadores em situação de desemprego ou emprego temporário. Olhando para os italianos (todas as faixas etárias) vê-se que $12,7 \%$ estão desempregados e $12,2 \%$ são temporários, o que perfaz um total de $24,9 \%$. E dentre os portugueses (todas as faixas etárias) verifica-se que $15,5 \%$ estão desempregados e $17,7 \%$ são temporários, o que traz um total de 33,2\% nestas precárias condições. Se mirarmos para os jovens entre 15 e 24 anos a situação é ainda mais grave: $57,7 \%$ dos jovens espanhóis até 24 anos estão desempregados e $26,2 \%$ são temporários, perfazendo um total de $83,9 \%$. No caso dos jovens italianos $41,6 \%$ estão desempregados e 31,0\% são temporários, o que dá um total de $72,6 \%$. Já dentre os jovens portugueses $36,8 \%$ estão desempregados e 41,7\% são temporários, demonstrando 78,5\% de trabalhadores jovens nessa situação (CASADEl, 2014, on-line).

Figura 1 -Mapa da Europa com as taxas de desemprego de cada país, de fevereiro de 2014

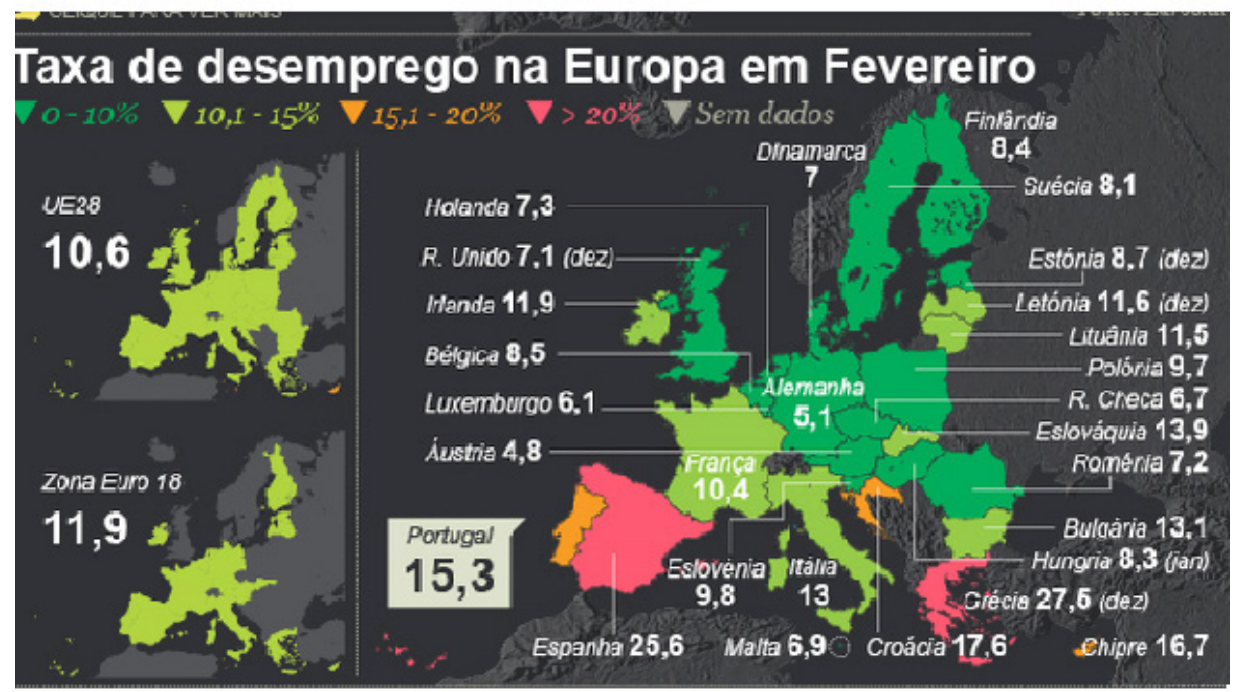

Fonte: FONSECA, 2014, online. 


\section{temporolis}

Todos estes dados atestam o desastre social, no lado do mundo tido como "mais desenvolvido", provocado pela crise estrutural do capital.

\section{A CRISE ENRAIZADA NA AMÉRICA LATINA E CARIBE}

E o outro lado do mundo? Saindo do continente europeu e aterrissando na América Latina e Caribe, o que se vê por aqui?

p. 5):

Segundo a Organização Internacional do Trabalho (OIT, 2013,

La pérdida de dinamismo económico impactó al mercado de trabajo en América Latina y el Caribe. En 2013 los indicadores laborales revelan un estancamiento del progreso que había caracterizado los años anteriores. La región corre el riesgo de perder una oportunidad de avanzar en la generación de más y mejores empleos. Estamos en un momento positivo pero desafiante. La tasa de desempleo urbano registra mínimos históricos de 6,3\% en 2013. Pero esa leve reducción en comparación al 6,4\% de 2012 no se debió a la generación de nuevos puestos de trabajo, sino a una baja en la participación en la fuerza laboral. Los salarios crecen menos que en años anteriores, la informalidad no se reduce, la productividad está creciendo por debajo del promedio mundial, y aumenta la desocupación de los jóvenes en zonas urbanas.

Mesmo para aqueles que estão no mercado de trabalho, o próprio Documento alerta que é preciso atentar-se para as condições deste emprego - 130 milhões destes trabalhadores estão no mercado informal na América Latina e Caribe - três de dez trabalhadores da região não possuem nenhuma cobertura de seguridade social, nem de saúde, e nem de pensões, ainda que esta cobertura tenha aumentado de 2011 para 2012 em aproximadamente 2,2 milhões de trabalhadores. (OIT, 2013). Assim, temos que: "Los últimos datos disponibles indican que los avances en materia de formalización de los mercados laborales se han estancado y persiste la tasa de $47,7 \%$ de los ocupados no agrícolas que trabajan en condiciones de informalidad."(OIT,2013, p. 15).

Em relação ao desemprego, ainda, há que se dizer que este atinge significativamente aos jovens latino-americanos: "Se observo un incremento de la tasa de desempleo juvenil urbano de tres décimas entre 2012 y 2013 de 14,2\% a 14.5\%. Esto significa que había unos 6.6 
millones de jóvenes desempleados en las áreas urbanas de la región en 2013."(OIT, 2013, p. 15).

No que se refere à questão salarial a média das remunerações registrou um aumento modesto de $1 \%$ em 2013 , menor que $2,1 \%$ no mesmo período de 2012. Os salários mínimos também cresceram menos, a média do salário mínimo real aumentou 2,6\%.

No Brasil, embora haja alguns resultados positivos no que se refere à redução da pobreza extrema na última década, observa-se uma retração nos dados de 2013, como veremos a partir de dados do Instituto de Pesquisa Econômica Aplicada (IPEA), que publica o número de indigentes no País (pessoas sem rendimento suficiente para compra de uma cesta mínima de alimentos, de acordo com valores regionais). Os dados mostram que houve um aumento de 10,08 miIhões, em 2012, para 10,45 milhões em 2013. Estes dados foram calculados pela Pesquisa Nacional por Amostra de Domicílios (PNAD).

\section{Gráfico 2- Evolução do número de miseráveis}

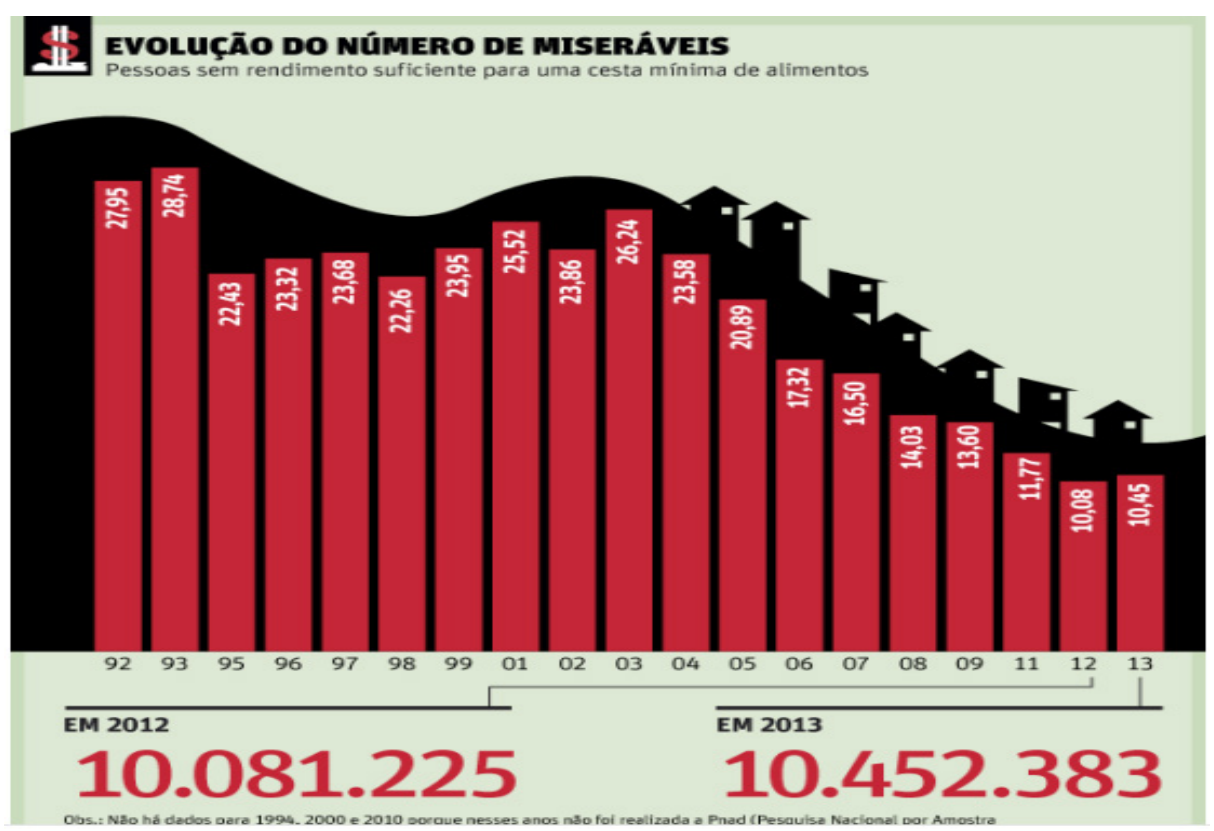

Fonte: EVOLUÇÃO..., 2014, on-line.

Como se observa a crise atinge este lado do mundo e o escopo 


\section{temporalis}

das políticas sociais existentes, opção dos governos "social-liberais" (CASTELO, 2013) só consegue, no limite, amenizar a pobreza absoluta.

\section{A ORIENTAÇÃO TEÓRICO-METODOLÓGICA DAS POLÍTICAS SOCIAIS BRASILEIRAS}

Fagnani (2005) aponta três momentos que caracterizaram a entrada do pensamento neoliberal no Brasil: o do curto período do governo Collor (1990-1992); o de Fernando Henrique Cardoso (FHC) desde a sua gestão no Ministério da Fazenda até o final de seu segundo mandato como presidente com término em 2002; e o do governo de Luís Inácio Lula da Silva, que se finda em 2010. Acrescentamos uma continuidade ao terceiro período com o governo de Dilma Rousseff que se inicia em 2011 e permanece até os dias atuais.

O governo Lula mantém e aprofunda a orientação macroeconômica de FHC, implementando o que Castelo (2013, p. 247) chama de "[...] segunda variante ideológica do neoliberalismo - chamada social-liberalismo", em poucas palavras, Estado e mercado amalgamados com a suposta intenção de combinar crescimento econômico e ganhos sociais concomitantemente.

Para crescer economicamente o governo Lula privilegiou o setor agroexportador, setor que parece que lhe foi imposto pela economia global e à qual vem se subordinando, o agronegócio passa a ser um grande aliado ao "desenvolvimento" nacional, e, desta forma, não se fala mais em reforma agrária. E para atenuar a pobreza absoluta este governo implanta e consolida o Programa Bolsa Família3, efetua uma política de valorização do salário mínimo, dentre as principais medidas adotadas nesta direção.

Ainda que possa se observar alguns impactos, que denominaríamos de efeitos compensatórios dos programas de transferência de renda implantados, sobretudo o Bolsa Família, e de medidas como o aumento do salário mínimo, da formalização de trabalhadores (o que já se observa uma regressão), há que se dizer que essas medidas não intencionaram a transformação das estruturas que criaram e mantêm a pobreza brasileira.

3 O Programa Bolsa Família instituído em 2004 torna-se o maior programa de transferência de renda brasileiro, voltado para o atendimento de famílias pobres e extremamente pobres. Para uma análise crítica acerca deste Programa, consultar: SANT'ANA; MUSTAFA, 2013. 
Como se demonstrará o governo Lula executa o que Filgueiras e Gonçalves (2007) intitulam como "modelo liberal periférico", mantendo a política econômica do segundo mandato de Fernando Henrique Cardoso (1999-2002) respaldada no ajuste fiscal permanente, nas metas de inflação e no câmbio flutuante.

O governo Lula para além de comprometer-se em transferir renda (parca - 0,46\% do Produto Interno Bruto) via Bolsa Família aos mais pobres, compromete-se em transferir renda (abundante) ao capital financeiro através do pagamento dos juros dos títulos da dívida pública. Para se ter uma ideia de 1995 a 2002, governo FHC, a dívida pública líquida mais do que dobrou, partindo de $29,5 \%$ do Produto Interno Bruto (PIB) para 60,4\% do PIB. Já nos governos Lula-Dilma a dívida saiu de 60,4\% para 34,9\% em junho de 2014. (BRASIL DEBATE, 2014, online). Este dado comprova o compromisso dos governos LulaDilma com a política fiscal. Neste sentido, pode-se indagar: seguindo a lógica do mercado, quem teve mais responsabilidade fiscal, FHC ou Lula-Dilma?

A título de deixar mais claro, o quadro a seguir comprova:

Quadro 1 - Evolução Relação Dívida/PIB

\begin{tabular}{|l|l|l|}
\hline & FHC & LULA \\
\hline Média Crescimento PIB & $2,29 \%$ & $3,47 \%$ \\
\hline Evolução Relação Dívida/PIB & $\begin{array}{l}29,35 \%-50,47 \%-> \\
+72 \%\end{array}$ & $\begin{array}{l}50,47 \%-44,78 \% * * ~-> \\
-11 \%\end{array}$ \\
\hline
\end{tabular}

*Média aritmética dos anos 2002 e 2009, levando em consideração estimativa do mercado para 2009, e sem considerar a de 2010.

** Com base na relação dívida pública de Outubro de 2009 (última aferição observada).

Fonte: todos os dados são referentes ao BC-DEPEC do Banco Central do Brasil e compilados pelo Conselho Regional de Economia de São Paulo. (GASPARI, 2010, on-line).

O montante financeiro destinado ao pagamento da dívida pública em 2014 foi de $R \$ 251,1$ bilhões, 35,10\% a mais que em 2013, que foi de $\mathrm{R} \$ 185,8$ bilhões (PATU, 2015, online). Portanto, vê-se que do Orçamento de 2014, o setor financeiro abocanha $42 \%$ (interesses e amortizações da dívida pública), enquanto a política pública de saúde fica com $4,28 \%$, a política de educação com $4,18 \%$, a política de assistên- 


\section{tompordlis}

cia social com 3,18\%, a Habitação 0,01\%, o que se intitula pelo governo federal de Organização Agrária fica com 0,32\%4. Estes dados elucidam a orientação do governo de Dilma Roussef, a qual mantém e perpetua a hegemonia do capital, diga-se do capital financeiro. Ao mesmo tempo nos ajuda a delinear o caráter das políticas sociais neste governo, pois, com tão parcos recursos quais direitos sociais se pode garantir?

Outro dado importante para se mostrar é o quanto o governo deixa de arrecadar com as desonerações da folha de pagamento. Em 2013, os cofres públicos deixaram de receber R\$12,3 bilhões, já em 2014 este valor salta para $\mathrm{R} \$ 21,6$ bilhões, uma alta de 75,6\% (PATU, 2015, online).

Enquanto a presidente Dilma deixa de arrecadar com as desonerações da folha de pagamento como se acabou de demonstrar, ela lança no findar de 2014 um pacote de cortes em direitos previdenciários, materializado pelas Medidas Provisórias (MP) n 664/2015 e nº $665 / 2015^{5}$, no intuito de economizar R\$18 bilhões, segundo o governo. Ora, a equação é simples: os R\$21,6 bilhões deixados de se arrecadar em 2014 com as desonerações cobriria com folga o que se pretende agora economizar sob o argumento de fraudes na previdência social, especificamente no seguro-desemprego, bem como de um sistema generoso de pensões. Delgado (2015, on-line) diz que estes

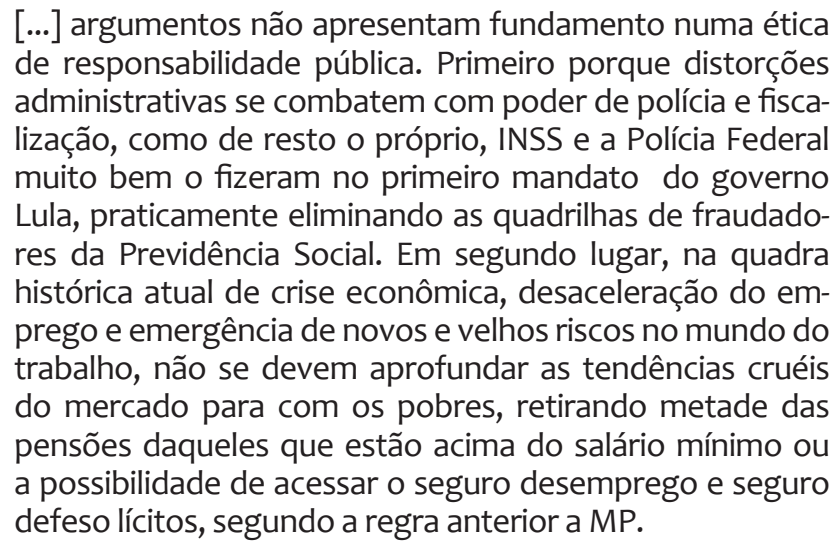

Após atentar contra os direitos dos trabalhadores através des-

4 Percentuais calculados a partir dos dados orçamentários disponíveis no Portal da Transparência do Governo Federal - (BRASIL, online).

5 Estas medidas já estão vigorando com suas regras restritivas a partir de $1^{\circ}$ de março de 2015, embora ainda em tramitação no Congresso Nacional. 
tas medidas, às quais já demonstramos não serem necessárias para a economia dos $\mathrm{R} \$ 18$ bilhões anunciadas pelo governo se as desonerações forem cessadas, a referida presidente num lapso de consciência acaba de apresentar ao Congresso outra Medida Provisória, a de $\mathrm{n}^{\circ}$ 669/2015, esta trata da "[...] revogação de um conjunto de desonerações previdenciárias concedidas desde 2012 e consolidadas também por Medida Provisória[...]." (DELGADO, 2015, online). Entretanto, o presidente do Congresso, senador Renan Calheiros, devolve a Medida, sob o argumento de que não se tratava "[...] de matéria de urgência e relevância justificativa de tramitação de uma MP.” (DELGADO, 2015, online). Ora, quando se trata de medida que atinge milhões de trabaIhadores o atual presidente do Congresso brasileiro não devolveu a proposta, mas quando se trata de medida que atinge os empregadores a matéria não é tida como urgência.

A partir destes dados ontológicos, o que se pode inferir acerca das políticas sociais brasileiras?

É claro e notório que a orientação teórico-metodológica das políticas sociais na era Lula-Dilma não se respalda em direitos universalizados, mas sim, no princípio da focalização, seguindo os preceitos neoliberais para este campo. Nesta direção passam a orientarem-se pela lógica da focalização na pobreza extrema, a exemplo dos programas de transferência de renda, estigmatizando os pobres, mantendo e naturalizando a pobreza, e, ainda, responsabilizando o indivíduo pelo seu bem-estar. Outra estratégica seguindo a esta lógica (ilógica) é a privatização das políticas sociais - segundo Soares (2001, p. 91) "[...] tem levado a dualidade no acesso aos serviços, criando um setor público para pobres, sem recursos e cada vez mais desfinanciado e [...] um setor privado para quem pode pagar."

Ainda é preciso apontar que o sistema tributário brasileiro é regressivo - as rendas mais baixas são mais tributadas que as mais altas, isto mostra a natureza regressiva e de desigualdade da estrutura tributária brasileira, o que reforça a desigualdade social. Os preceitos constitucionais da reforma tributária brasileira não foram respeitados por nenhum governo, o que houve foram contrarreformas tributárias, segundo Salvador (2010). Para se ter uma ideia, segundo dados do Instituto Brasileiro de Planejamento e Tributação (IBPT) (apud NASCIMENTO, 2014, online), a maior parte da arrecadação 53,8\% é proveniente de quem recebe até três salários mínimos, e o total de brasileiros que encontra-se nessa faixa de renda é de $79 \%$, enquanto 


\section{temporalis}

somente $16 \%$ da arrecadação corresponde aos que perfazem a renda entre cinco e dez salários mínimos. Isso ocorre porque o Brasil tem um sistema tributário concentrado no consumo.

Desta feita, como bem nos lembra Vianna (apud BEHRING; ALMEIDA, 2010), a concepção "liberal e liberal revisitada" priorizam a liberdade em detrimento da igualdade - então, o objetivo se traduz na ampliação de oportunidades para que todos possam caminhar pelas “próprias pernas". Segundo esta autora há duas estratégias de enfrentamento da questão social conforme esta lógica:

A primeira, o empreendedorismo - fundado em três premissas: 1 -"A questão social se define de forma reducionista, como pobreza" (VIANNA apud BEHRING; ALMEIDA, 2010, p. 148) e esta "[...] é entendida como uma situação em que indivíduos se encontram por falta de certos dotes" (VIANNA apud BEHRING; ALMEIDA, 2010, p. 148), perspectiva totalmente desassociada da estrutura econômica e social. Estes "dotes" devem ser adquiridos através das capacitações e através destas o indivíduo deve conseguir ultrapassar as condições de pobreza. 2 - As políticas universais “[...] são formas anacrônicas e ineficazes de lidar com a questão social [...] inovadoras são as estratégias que se dirigem aos indivíduos, a pequenos grupos, a segmentos específicos da população pobre [...]." (VIANNA apud BEHRING; ALMEIDA, 2010, p. 148). 3 - Inclusão se traduz em estar no mercado de trabaIho, seja formal, informal, não importam as condições. Inclusão não significa mais ter acesso à "[...] direitos civis, políticos, sociais [...]", mas sim ser "[...] produtor/consumidor de mercadorias [...]" (VIANNA apud BEHRING; ALMEIDA, 2010, p. 148) (não importam quais sejam). Desta forma, o que possibilita a "[...] inclusão não é mais a carteira de trabalho [...]" (VIANNA apud BEHRING; ALMEIDA, 2010, p. 148), mas o CPF, documento necessário para viabilizar os empréstimos. (VIANNA apud BEHRING; ALMEIDA, 2010).

E a segunda estratégia, a chamada a "la Madre Teresa de Calcutá" (VIANNA apud BEHRING; ALMEIDA, 2010, p. 149) - a política social é política assistencial para os pobres - com o fim de aliviar a pobreza, o que não tem nenhuma relação com a concepção universal de política social (VIANNA apud BEHRING; ALMEIDA, 2010).

Outra tendência em curso é a criminalização dos pobres - observa-se o aumento do número de presos e do investimento em segurança pública e privada no Brasil. Informações do Departamento 
Penitenciário Nacional (apud PAULO NETTO, 2010) mostram que o encarceramento no Brasil aumentou de 140.000 em 1995 para 361.500 em 2005, sendo que no primeiro semestre de 2009 já perfazia um total de 469.807. Será que o Estado Social está sendo substituído pelo "Estado Penal"? (WACQUANT, 2007).

Para Paulo Netto (2010, p. 24) vivemos em tempos de barbárie, cuja face se representa pela "[...] articulação orgânica de repressão às 'classes perigosas' e assistencialização minimalista das políticas sociais dirigidas ao enfrentamento da 'questão social'."

\section{CONSIDERAÇÕES FINAIS}

Nestes tempos os desafios são muitos... Como articular os princípios do Projeto Ético Político ${ }^{6}$ do Serviço Social no campo das Políticas Sociais?

Mota (2010, p. 27) nos aponta

[...] estratégias inerentes ao nosso projeto profissional:

I. Resgatar a diferença entre iniciativas de enfrentamento à pobreza e estratégias de superação das desigualdades [...].

I. Tratar essas questões no horizonte dos projetos de emancipação política e humana [...] compreendendo o exercício dos direitos como uma mediação política anticapitalista e não como um projeto societal.

Essas estratégias nos parecem fundamentais diante do contexto que apresentamos, pois, o que se vê, sobretudo na realidade brasileira nos governos Lula-Dilma, é o predomínio de ações pontuais para se enfrentar a pobreza absoluta. Não desprezamos a importância dessas ações para um país extremamente empobrecido como o Brasil, contudo, temos que avançar. E avançar em que sentido? No sentido de enfrentar a desigualdade social produzida e reproduzida cotidianamente neste país, desigualdade, fruto de uma histórica apropriação desigual das riquezas produzidas, diga-se de passagem, pela classe trabalhadora. Como se demonstrou esta classe fica com as migalhas da riqueza nacional e, ainda, é a que paga a conta, devido aos impostos que lhe são tributados.

6 Os assistentes sociais brasileiros construíram coletivamente um projeto ético-político que contém os princípios ético-políticos que devem respaldar o exercício profissional desta categoria. 


\section{tempordlis}

Lutar pelos direitos sociais, como bem nos coloca Mota (2010) é apenas uma mediação necessária, mas não retrata o projeto de sociedade que defendemos, uma vez que este projeto não se limita a emancipação política, mas deve avançar rumo à emancipação humana.

Termino com duas reflexões de dois importantes autores do Serviço Social:

Maria Lúcia Barroco (2011, p. 215-216):

Os pilares que sustentam o nosso Projeto Ético-Político em sua dimensão de ruptura - o marxismo, o ideário socialista da emancipação humana, o compromisso com as classes trabalhadoras e com a realização de um Serviço Social que atenda os seus reais interesses e necessidades, a busca de ruptura com o conservadorismo em todas as suas formas constituem o nosso mais valioso patrimônio que, espero, possamos cuidar dele com muito amor e coragem.

E de José Paulo Netto (2010, p.31), que nos diz: "Se a barbárie é a perspectiva real e imediata, o socialismo é uma alternativa possível e o possível é também constitutivo do real, tem raízes na realidade."

E por fim retorno ao final do poema de Moacyr Félix, o mesmo que inicia este trabalho:

O poeta defende

o direito de andar

até o outro lado da vida em que o homem é o seu avesso o chão de seu próprio mar

e a verdade a rosa nua

solta na praia e na rua como um convite a bailar.

O poeta defende o direito de amar. (Moacyr Félix - Canto para as transformações do homem, 1964).

\section{REFERÊNCIAS}


BARROCO, M. L. Barbárie e neoconservadorismo: os desafios do projeto ético-político. Serviço Social \& Sociedade, São Paulo, n. 106, p. 205-217, abr./jun. 2011.

BRASIL. Controladoria-Geral da União. Portal da Transparência. Disponível em: <http://portaldatransparencia.gov.br/>. Acesso em: 12 mar. 2015.

BRASIL Debate. Governos FHC ou Lula-Dilma: quem tem responsabilidade fiscal? 13 out. 2014. Disponível em: <http://brasildebate.com.br/ fhc-ou-lula-dilma-quem-tem-responsabilidade-fiscal/>. Acesso em: 12 mar. 2015.

CASADEI, J. Desemprego na Europa: números mostram uma situação tenebrosa, principalmente na Espanha. 25 jan. 2014. Disponível em: $<$ https://jcasadei.wordpress.com/2014/01/25/desemprego-na-europa-nmeros-mostram-uma-situao-tenebrosa-principalmente-na-espanha/>. Acesso em: 12 jul. 2014.

CASTELO, Rodrigo. O social-liberalismo: auge e crise da supremacia burguesa na era neoliberal. São Paulo: Expressão Popular, 2013.

DELGADO, G. C. Crise e impasse desconstroem política social instituída a partir de 1988. Correio da Cidadania, São Paulo, 11 mar. 2015. Disponível em: <http://www.correiocidadania.com.br/index.php?option=com_content\&view=article\&id=10582: manchete110315\&cati$\mathrm{d}=34$ :manchete $>$. Acesso em: 11 mar. 2015.

EVOLUÇÃO do número de miseráveis no Brasil. DesmascarandoGloboFolha, 6 nov. 2014. Disponível em: <http://desmascarandoglobofolha.com/2014/11/06/evolucao-do-numero-de-miseraveis-no-brasil/>. Acesso em: 7 nov. 2014.

FAGNANI, E. Política social no Brasil (1964-2002): entre a cidadania e a caridade. 2005. 604 f. Tese (Doutorado em Ciências Econômica) Instituto de Economia, Universidade Estadual de Campinas, Campinas, 2005.

FÉLIX, M. Canto para as transformações do homem. Rio de Janeiro: Civilização Brasileira, 1964.

FILGUEIRAS, L.; GONÇALVES, R.A economia política do Governo Lula. São Paulo: Contraponto, 2007. 


\section{temporalis}

FONSECA, T. O mapa mais preocupante da Europa: o do desemprego. Dinheiro Vivo, Porto, 8 jan. 2014. Disponível em: <http://www.dinheirovivo.pt/graficos/interior.aspx?content_id=3883594>. Acesso em: 10 jan. 2014.

GASPARI, E. Comparação Lula X FHC 2: dívida pública e PIB. Ponto \& Contraponto, 9 jan. 2010. Disponível em: <http://pontoecontraponto. com.br/2010/01/09/>. Acesso em: 11 jul. 2014.

HARVEY, D. O neoliberalismo: história e implicações. Tradução de Adail Sobral e Maria Stela Gonçalves. São Paulo: Edições Loyola, 2008.

IAMAMOTO, M. V. Estado, classes trabalhadoras e política social no Brasil. In: BOSCHETTI, I. et al. Política social no capitalismo: tendências contemporâneas. 2. ed. São Paulo: Cortez, 2009.

MÉSZÁROS, I. A crise estrutural do capital. São Paulo: Boitempo, 2011. MOTA, A. E. Redução da pobreza e aumento da desigualdade: um desafio teórico-político ao Serviço Social brasileiro. In: . (Org.). As ideologias da contrarreforma e o Serviço Social. Recife: Ed. Universitária da UFPE, 2010.

NASCIMENTO, B. Mais da metade da arrecadação tributária do país é sustentada pelos pobres. Correio Braziliense, Brasília, DF, 14 ago. 2014. Disponível em: <http://www.correiobraziliense.com.br/app/ noticia/economia/2014/08/14/, 442226/mais-da-metade-da-arrecadacao-tributaria-do-pais-e-sustentada-pelo-pobres.shtml. Acesso em: 12 mar. 2015.

OIT. Panorama laboral 2013. Lima: OIT: Oficina Regional para América Latina y el Caribe, 2013. Disponível em: <http://www.ilo. org/wcmsp5/groups/public/americas/rolima/documents/publication/ wcms_232760.pdf>. Acesso em: 6 nov. 2014.

PATU, G. Gasto de R\$2 251 bi com juros pagaria uma década de Bolsa Família. Folha de S. Paulo, São Paulo, 30 jan. 2015. Disponível em: <http://www1.folha.uol.com.br/mercado/2015/01/1583320-gasto-de-r251-bi-com-juros-pagaria-uma-decada-de-bolsa-familia.shtml>. Acesso em: 30 jan. 2015. 
PAULO NETTO, J. Uma face contemporânea da barbárie. In: ENCONTRO INTERNACIONAL “CIVILIZAÇÃO OU BARBÁRIE”, 3., 2010, Serpa. Anais... Serpa: 2010. Disponível em: <http://pcb.org.br/portal/ docs/umafacecontemporaneadabarbarie.pdf >. Acesso em: 12 mar. 2011.

.; BRAZ, M. Economia política: uma introdução crítica. São Paulo: Cortez, 2007.

PEREIRA, P. A. P. Política social do segundo pós-guerra: ascensão e declínio. Serviço Social \& Saúde, Campinas, v. 9, n. 10, p.1-10, dez. 2010. Disponível em: <http://www.bibliotecadigital.unicamp.br/document/ list.php?tid=554>. Acesso em: 20 nov. 2011.

SALVADOR, E. Fundo público e seguridade social no Brasil. São Paulo: Cortez, 2010.

SANT'ANA, R. S.; MUSTAFA, P. S. Assistência social e precarização do trabalho: a perversa opção brasileira. In: NAVARRO, V. L,; LOURENÇO, E, A. S. (Org.).O avesso do trabalho III: saúde do trabalhador e questões contemporâneas. São Paulo: Outras Expressões, 2013.

SOARES, L. T. R. Os custos sociais do ajuste neoliberal: ajuste neoliberal e desajuste social na América Latina. Petrópolis: Vozes, 2001.

VASAPOLLO, L. Trabalho atípico e a precariedade. São Paulo: Expressão Popular, 2005.

VIANNA, M. L. T. W. Reforma do Estado e política social: notas à margem do tema. In: BEHRING, E.; ALMEIDA, M. H. T. (Orgs.). Trabalho e seguridade social: percursos e dilemas. Rio de Janeiro: Ed. UERJ; São Paulo: Cortez, 2010.

WACQUANT, L. Punir os pobres: a nova gestão da miséria dos Estados Unidos. Tradução de Sérgio Lamarão. 3. ed. Rio de Janeiro: Revan, 2007. 
